\title{
Capacidade de atuar e legitimação do Estado democrático de direito na era da globalização*
}

\author{
FRANK RICHARD PFETSCH**
}

A atualidade dos países industrializados do Ocidente parece estar caracterizada por crises, rupturas, reviravoltas e abalos políticos estruturais (Kramer). Fala-se de "era da decadência” (Capra), de "virada de época”, de um ambiente apocalíptico, de uma "nova opacidade" (Habermas), de "crise de crescimento" (Beck), de uma "fase de transformações estruturais amplas e profundas", ou de uma "crise da democracia e da política". ${ }^{1}$ Encontra-se ainda quem escreva sobre o "fim da modernidade", o "ocaso dos estados nacionais capazes de prover as aspirações sociais”, a "desconstrução do Estado democrático e social” (Lyotard). Proclama-se o "fim da história” (Fukuyama) ou o "fim da utopia” (Fest). Não é exagerado estabelecer-se um paralelo entre esses sentimentos apocalípticos e o ambiente fin-de-siècle do final do século passado.

Todas essas caracterizações, oriundas de posições bem diversas, exigem ser explicitadas. Por uma parte, trata-se de macroagregados, como modernização, a modernidade, globalização, industrialização, história, utopia; de outra, agregados referidos à nação, como democracia, Estado social, Estado nacional. Desejo, aqui, concentrar-me nas questões politicamente relevantes e examinar tanto a caracterização da crise enquanto importante para uma teoria da democracia, como as estratégias operacionais - efetivas ou possíveis - que dela decorrem. O ponto fulcral é o Estado democrático de direito nas sociedades ocidentais industrializadas, sua capacidade de atuar e sua legitimidade no fogo cruzado dos desafios externos e das estratégias operacionais internas.

\section{Crise do Estado nacional}

John Hertz falava, já em 1969, da "crise do Estado-nação territorial” e Ernst-Otto Czempiel, no mesmo ano, referia-se à "soberania anacrônica”; Daniel Bell reforça: “O Estado-nação está-se tornando demasiado pequeno para os grandes

\footnotetext{
Rev. Bras. Polít. Int. 41 (2): 102-117 [1998]

* Traduzido por Estevão Chaves de Rezende Martins

** Professor de Ciência Política na Universidade de Heidelberg (Alemanha). Professor visitante do Programa de Pós-Graduação História das Relações Internacionais da Universidade de Brasília, 1997.
} 
problemas e grande demais para os pequenos problemas da vida” (Bell 1993, 11). Essas formulações revelam duas formas da evolução contemporânea: de um lado o aumento das atividades internacionais, que um estado nacional sozinho não dá conta de realizar; a abertura dos mercados, como conseqüência da constituição de um mercado interno europeu e da liberalização mundial do comércio, desencadeou processos que ignoram, em larga medida, a autoridade dos Estados nacionais. De outro lado, o Estado vê-se confrontado com o incremento de processos subnacionais, como os que transparecem tanto nos conflitos étnicos, nos movimentos autonomistas, e mesmo em secessões, como em processos de individualização. O Estado caiu prisioneiro, por assim dizer, da tenaz formada por essas quatro diferentes evoluções: - da periferia dos Estados membros da União Européia forçou-se maior concorrência em setores até então protegidos, mediante liberalização econômica tanto interna quanto externa; a renúncia a direitos soberanos insere-se, de qualquer forma, na lógica da integração supranacional tal como ela é praticada na União Européia (europeização); surgiu, contudo, uma assimetria: enquanto a União Européia desfraldava a bandeira da liberalização, ficou faltando uma política social e trabalhista comum, que compensasse os efeitos da liberalização. Política econômica e política social pertencem à "economia social de mercado" como gêmeos siameses, que estão agora separados;

- a liberalização generalizada do comércio, tal como praticada pelo GATT e agora pela Organização Mundial do Comércio - OMC (globalização) pressiona a concorrência interestatal, apesar das tendências protecionistas ainda subsistentes, e agrava as rivalidades na distribuição;

- no plano social interno, o Estado entra em crise justamente por força dessa situação de concorrência econômica externa, na medida em que os efeitos sociais perversos se multiplicam, como uma espécie de subproduto dessa concorrência externa, e na qual a política financeira se vê às voltas com a diminuição dos recursos a distribuir. A pressão sobre os sistemas estatais de prestações sociais se acentua com a reação das associações e, sobretudo, dos sindicatos, cobrando o atendimento de exigências e o cumprimento de promessas sociais (individualização);

- o potencial de conflitos transferiu-se da arena internacional para o campo interno (renacionalização) e põe aos governos nacionais novas e mais graves questões de segurança interna; a etnicização traz reivindicações de autonomia que precisam ser controladas; os custos da segurança interna aumentaram e os da segurança externa diminuíram.

Todos esses processos reduzem a capacidade de ação do Estado, para a qual ele tem de buscar compensações. A inaptidão a agir e a reagir evidencia-se em diversos níveis do sistema nacional (1997, Alemanha: reforma tributária e do sistema de saúde), regional (União Européia: fracasso no gerenciamento de crises e guerras como, por exemplo, na Bósnia) e internacional (Nações Unidas: Somália, Bósnia, conflitos no Oriente Próximo). 
O sistema político-administrativo dos Estados-nação ocidentais procura ir de encontro a essa perda de autonomia mediante três estratégias: no plano interior, tanto pela vinculação corporativa dos grupos sociais como pela renacionalização no sentido da vinculação de grupos minoritários e, no plano internacional, pela international governance. As três estratégias podem recuperar, para os governos nacionais, a capacidade de atuação que perderam para atores internos e externos (ver adiante).

\section{Capacidade de ação e legitimação}

As capacidades de ação e legitimação do Estado estão em proporção direta: a capacidade de agir, demonstrada pelo sucesso obtido, tem efeito legitimador. Um sistema político é aceito não apenas pela concessão de direitos e garantias ou pela participação, mas também por uma política bem sucedida. Em outras palavras: são importantes tanto os processos de formação de vontades e de tomadas de decisão (input) quanto os resultados (output). Busca-se conformar essas duas características do Estado através do recurso aos potenciais de gerenciamento (corporativismo, nacionalismo e international governance).

Se a política, no entanto, pode ser definida como o campo em que pequenos grupos de indivíduos dotados de competência para agir tomam, de acordo com certos interesses, decisões vinculantes para uma coletividade maior em um determinado território, é então possível identificar dois processos que modificaram o sistema nacional de decisão:

- de um lado, as decisões são tomadas por atores situados fora dos territórios nacionais, mas com efeito vinculante para os cidadãos do Estado; os governos já não mais decidem sozinhos o que é certo, correto e adequado para os cidadãos de seu próprio país. Tem-se agora tomadores de decisão (decision makers) internacionais e transnacionais;

- as decisões de Estados nacionais têm efeitos sobre os cidadãos de outros países, sem que estes tenham participado do processo de formação da vontade e de tomada de decisão. As conseqüências econômicas e ecológicas sobre os Estados vizinhos são aqui um exemplo, e elas têm aumentado em virtude dos grandes empreendimentos tecnológicos.

Resulta disso a permeabilidade do Estado, uma discrepância crescente entre os decisores e os atingidos pela decisão. Em outras palavras: o conjunto dos aptos a decidir já não mais coincide com o conjunto dos atingidos pela decisão, surgindo assim um déficit de legitimação e de eficiência que pode desestabilizar o Estado democrático. A política passou para as arenas interestatais, regionais e internacionais. Novos modelos da formação de vontade e de tomada de decisão desenvolveram-se. Decorreu disso uma espécie de anonimato da responsabilidade e competência na relação entre os atores políticos e a população. A identificação dos competentes para as medidas políticas e responsáveis por elas 
tornou-se mais difícil, em certos casos mesmo impossível; caem, com isso, as necessidades de justificação e as possibilidades de controle.

Como se pode descrever esses quatro processos causadores da transferência e provocadores de crise? Para tanto, é possível enunciar quatro teses: a da globalização, a da europeização, a da individualização, e a da etnicização.

\subsection{Globalização}

É difícil encontrar um outro conceito que esteja hoje tão na moda como o de globalização ou, em formulação mais radical: de "armadilha da globalização" (Martin/Schumann). É grande a diversidade do que se entende por ele.

Primeiramente, o aumento das imbricações econômicas tornou a “essência” do Estado mais vulnerável. O conceito clássico de Estado pressupunha, de início, a idéia de autarquia econômica (mercantilismo, fisiocracia etc.). Logo, o liberalismo considerou garantido o "bem-estar das nações" mediante a divisão internacional do trabalho e a liberalização do comércio exterior. Os operadores desse processo são organizações transnacionais, em particular os conglomerados multinacionais. Elas são vistas, de um lado, como a "consciência da opinião mundial”, como os "agentes locais do bem comum mundial” (Hedley Bull); de outro, como responsáveis pela miséria no Terceiro Mundo e pela impotência dos governos no Primeiro. As organizações não-governamentais internacionais - entrementes, já mais de 5.000 - tiram proveito da defasagem entre as bases territoriais da economia e passam por cima das normas estabelecidas pelos estados. Trata-se sobretudo do livre comércio internacional efetuado por agentes e empresários privados para além das fronteiras, tal como praticado pelos Estados Unidos desde a $2^{a}$ Guerra Mundial e adotado por instituições como o GATT/OMC, Banco Mundial, Nações Unidas etc. Essas atividades transnacionais se pautam pelas leis internacionais do mercado; a eficiência econômica otimiza ou maximiza as condições mundiais de produção e comercialização e não se restringe às circunstâncias do mercado interno. Um indicador dessa concepção da globalização são as taxas de crescimento do comércio mundial, maiores do que as do produto mundial bruto; o volume das exportações cresceu sobretudo na Europa Ocidental e na Ásia. Na maior parte dos países industrializados do Ocidente, o volume das exportações, nos anos noventa, é maior do que no período anterior à $1^{a}$ Guerra Mundial ou posterior à segunda. Constituem exceção apenas a Austrália, a Finlândia, a Suíça, a Inglaterra e os Estados Unidos, cujas exportações durante esses períodos foram ainda maiores. São os mercados financeiros e cambiais que apresentam uma expansão exponencial: o desempenho das bolsas internacionais ultrapassa o valor do comércio mundial em quarenta vezes (Busch, 1996, 23).

A implantação de unidades de produção, estimativa de custos, aquisição de matérias-primas são questões decididas em escala mundial e somente muito 
limitadamente submetidas a controles nacionais, mesmo se o estabelecimento físico continua dependente da legislação local. O capital é globalmente móvel, o estado é territorialmente vinculado. É também o Estado que tem de assumir os custos decorrentes de tais decisões como, por exemplo, o desemprego gerado pela mobilidade global da produção.

A globalização pode ainda dizer respeito aos fenômenos seguintes:

- a conexão mundial em rede, como no caso exemplar dos sistemas internacionais multimediais de informação (Internet). Transparece, aqui, sobretudo o assim chamado quarto fator da produção capitalista (sistema securitário, consultoria, assessoria jurídica etc.), além do capital, trabalho e tecnologia. As novas tecnologias condicionam o desenvolvimento da sociedade industrial para a sociedade de informação;

- o modelo do Estado europeu se difundiu mundo afora. Hedley Bull fala da "expansão do sistema estatal europeu por todo o globo e de sua transformação em um sistema de Estado de dimensão global (Bull, 1977). De forma semelhante, Anthony G. McGrew retoma esse conceito, estendendo-o para o âmbito social, ao defini-lo: "Falar de política global é afirmar que há processos de globalização em curso que, de algum modo, contribuem para a globalização da atividade política. Globalização diz respeito à multiplicidade das relações e interconexões entre os Estados e as sociedades que formam o sistema mundial.” (McGrew, 1993, 23). O conceito abrangeria tanto o alcance (global, mundial) como a intensidade com que se dão as interações entre Estados $e$ sociedades;

- a globalização pode ainda incluir, de forma genérica e para além do campo econômico, a difusão mundial de qualquer processo político, social, econômico, cultural ou tecnológico, como transporte, comunicação, produção, fluxos financeiros, transferência tecnológica ou de armamentos, enfim, tudo o que possa ter relação internacional, como população mundial, migração, meioambiente, pobreza/subdesenvolvimento, proliferação de armas nucleares etc. Tem-se, aqui, o sentido da densidade do fenômeno transfronteiriço mundial referido a questões transnacionais vistas como "problemas mundiais" e feitas objeto das respectivas conferências mundiais da ONU. Outras expressões usadas são, ainda, universalização e mundialização.

Globalização é, por conseguinte, um conceito abrangente de largo espectro (catch all concept), que pode ser livremente formulado de forma ampla ou restrita. Na crescente bibliografia sobre a globalização, predomina a posição de que os processos intergovernamentais e transnacionais alcançaram influência cada vez maior sobre a política interna dos Estados e limitaram o espaço de ação política (Busch, 1996, 9). Varia, contudo, a estimativa dos efeitos da globalização, de acordo com a posição assumida: economistas liberais/livre-cambistas (Sachs/Warner, 1995, Ohmae, 1990) vêem prevalecer os benefícios de bem-estar, neomarxistas e 
keynesianos (Strange, 1995, Scharpf, 1996) receiam a perda de confiança e de soberania do Estado democrático, acompanhada de crises sociais; por fim, representantes da escola intervencionista (Boyer/Drache, 1996, Glyn, 1995) consideram existir boas chances para a competência reguladora do Estado.

\subsection{Europeização - Regionalização}

A constituição de uma comunidade regional sob a forma de Comunidade Européia, como é sabido, conduziu a uma transferência de soberania nacional para instituições interestatais supranacionais, que retirou do âmbito de decisão nacional certa competência. Isso diz respeito, em especial, às políticas tornadas comunitárias, como no caso do mercado interno da União Européia. A transformação ou metamorfose das relações entre os Estados membros e a Comunidade é vista com reservas por certos teóricos, relativamente à legitimação democrática (Weiler, 1991), por outros, pelo fato de haver falta de capacidade de gerência e controle por parte do Estado com relação às corporações econômicas (Scharpf, 1994). Wessels (1992) explica a cooperação entre os Estados membros especialmente pelo fato de que ganhariam mais dessa forma do que seria possível no comércio unilateral. Wallace e Wallace (1996, 453/4) consideram que o sistema estatal europeu foi transformado pelo desempenho econômico-tecnológico e pela hesitante transferência de funções de cada Estado para as instituições européias. Essas transferências formais de direitos soberanos significariam um risco para a identidade nacional.

A União Européia pode ser descrita como um sistema dinâmico de níveis múltiplos, que evidencia de modo especial o deslocamento dos processos de negociação e de decisão políticas. Cada Estado particular insere-se em um edifício comunitário e recebe, em contrapartida, direitos de co-gestão em setores políticos sobre os quais, isoladamente, não teria como exercer a mesma influência. O sistema de níveis múltiplos que assim se constitui (municípios, regiões/províncias, Estados, união) é estruturado, de acordo com o princípio da subsidiaridade, em diversas áreas de jurisdição e cuida de que, mediante a formação da comunidade e a redistribuição, surja um sistema político mais unitário, que represente uma forma mista de supranacionalidade e intergovernabilidade. Na intergovernabilidade, os governos continuam sendo os atores principais, na supranacionalidade a política nacional é diluída na comunidade.

De acordo com o direito constitucional, as competências podem ser transferidas para a União Européia mediante emendas à Constituição. Isso já aconteceu antes. Existem estimativas de que cerca de 80\% das decisões relativas ao mercado interno já se tornaram direito comunitário. Do ponto de vista do Estado nacional, isso significa que boa parte da legislação de política econômica passou para a Comunidade. A capacidade de ação dos Estados membros foi absorvida pela política coordenada. 
Como se dá, então, a legitimação dessa União Européia? Para responder a essa questão faz-se necessário recordar os fundamentos dos sistemas constitucionais liberais. O constitucionalismo moderno esteia-se em dois pilares: a garantia de direitos fundamentais e da pessoa humana e o controle do poder. Nos tratados europeus, os direitos humanos estão inscritos no inventário dos valores básicos. O controle do poder, no sistema político europeu, dá-se, primeiramente, não a partir do corpo legislativo, mas do conjunto do sistema de instituições. A Comissão e o Conselho podem pôr-se em cheque, tanto quanto a Corte Européia de Justiça, o Conselho e a Comissão. Também o Parlamento Europeu ganhou mais direitos de controle no Ato Único Europeu e nos tratados de Maastricht. Pode-se dizer, pois, que estão dados os requisitos básicos da legitimação de acordo com a concepção democrática liberal. Isso não satisfaz, todavia, às exigências de legitimidade democrática segundo a forma própria aos Estados nacionais. À União Européia aplica-se, por conseguinte - como, aliás, a qualquer outra instituição internacional semelhante - um conceito restrito de democracia.

\subsection{Individualização}

A tese da individualização deita suas raízes no Iluminismo, que fixou como meta a autonomia do indivíduo. Na medida em que a emancipação do indivíduo progrediu, o agir sintonizado com a comunidade perdeu importância. Individualização significa aqui a superação do efeito vinculante de macroorganizações e a fragmentação destas em unidades menores, ao tempo em que diminui a solidariedade e se enfraquecem as estruturas tradicionais da família. São sintomas dessa evolução a diferenciação dos grandes agregados sociais, o abandono da prática religiosa, da atividade sindical e da política partidária, a perda da identidade do cidadão com partidos políticos, o aumento do contingente de eleitores indecisos etc. Por via de conseqüência, uma série de grupos ganha importância e peso na defesa e na sustentação de interesses setoriais e impõe ao Estado novos desafios. A política dos grupos de interesse com poder de veto dificulta a formação de consenso e só admite decisões mínimas com o menor denominador comum. A garantia constitucional de espaço de liberdade para os indivíduos, de autonomia para os grupos sociais pode restringir o campo de atuação do Estado na medida em que as corporações busquem seus objetivos egoístas sem levar em conta a comunidade (Estado corporativo). O dilema estatal consiste na tensa relação em que se encontram a autolimitação do Estado, de um lado, e o respeito pelo bem comum, de outro. Esse dilema não é novo - ele dominou o debate sobre a ingovernabilidade nos anos 70 - mas agravou-se com a intensificação da concorrência.

Como reflexo da fragmentação social, pode dar-se, também, dispersão em atores estatais e semi-estatais. Nas democracias ocidentais, os governos podem ser bloqueados pelas coalizões ou pelas interdependências políticas federais. Katzenstein fala de um Estado semi-soberano e Scharpf da armadilha da 
interdependência. Os impasses na política financeira forçam o Estado a transferir custos para os agentes econômicos privados. Isso fica claro nos sistemas de saúde, de educação e de seguro social.

\subsection{Renacionalização}

Nas democracia ocidentais étnica e/ou culturalmente heterogêneas, os movimentos autonomistas dos grupos minoritários também entram em cena. $\mathrm{Na}$ Irlanda do Norte (católicos, protestantes), na Espanha (País Basco, Catalunha, Andaluzia), na Bélgica (flamengos, valões), na França (Córsega), grupos subnacionais pugnam por suas exigências de autonomia e autodeterminação diante do Estado central, em parte, usando meios terroristas. É certo que se pode tomar como regra que as democracias, por causa de sua maior capacidade de administrar conflitos, melhor ofereceriam soluções pacíficas. Elas deveriam, no entanto, ser concedidas pelos governos e requerem alto grau de flexibilidade e de tato.

Lidar com os grupos étnicos é mais dramático nas sociedades em desenvolvimento, que não dispõem de tais mecanismos de operação. A universalização do modelo ocidental de civilização levou também a que os mais modernos meios de comunicação fizessem chegar imagens à menor das aldeias africanas ou ao mais remoto recanto da Amazônia brasileira. A imbricação tecnológica multimedial por certo acarretou a unificação do mundo tecnológico, mas não a universalização do respectivo modelo cultural. Pelo contrário, em muitos Estados, forças se lhes opõem, sob a forma de fundamentalismos religiosos ou de nacionalismos étnicos, postos em atividade para preservar herança cultural autêntica e para contrapor-se à experiência da alienação provocada pela modernização no sentido ocidental. Os responsáveis por essa modernização não foram sempre elites ocidentais, mas, também, elites do Terceiro Mundo. O kemalismo na Turquia ou a Revolução Branca no Irã foram tentativas fracassadas de ocidentalização das elites locais. A Frente Islâmica da Salvação (FIS) na Argélia, o Partido do BemEstar de Erkaban, na Turquia, o governo dos mulás do aiatolá Khomeini no Irã, o partido Ba'ath de Saddam Hussein no Iraque são alguns exemplos, no universo islâmico, de reação à globalização ocidental e de reforço da identidade cultural (e, certamente, também, de poder pessoal) contra a uniformização e predominância da hegemonia econômica, política e cultural do Ocidente.

\section{Campos de atuação da atividade estatal organizada}

Como deve o Estado reagir a esses desafios? Será que ele deve mesmo reagir, justamente se o fortalecimento de atores sociais não-estatais pertence à essência da sociedade civil? A necessidade da capacidade estatal de operar resulta das carências provocadas pelo internacionalismo irrestrito do capitalismo. Até a teoria econômica liberal requer a competência reguladora do Estado para aqueles 
setores em que o mercado não pode garantir o bem comum. Essa exigência ganha importância na medida em que as transações se realizam sem levar o Estado em conta e em que as reivindicações sociais se dirigem a ele. O espaço de atuação do Estado será analisado sob três pontos de vista: função, transformação e operação.

\subsection{Funções do Estado}

O Estado liberal pluralista experimenta, desde os anos sessenta, uma espécie de renascimento. Numerosos argumentos concorrem para essa tese.

O Estado nacional continua sendo o destinatário principal das exigências de bem-estar geral; o aumento dos recursos, mediante incremento da participação do estado, e seu investimento, permanecem no âmbito das jurisdições governamentais. Os problemas cruciais das sociedades industriais ou pós-industriais (crescimento econômico, emprego, seguridade social, fornecimento de matéria prima etc.) recaem, afinal, por sobre os governos nacionais. Mesmo nos processos de integração regional, o Estado é o destinatário mais importante das reivindicações nos setores de segurança, bem-estar econômico e justiça social.

O princípio do Estado nacional ainda prevalece na diplomacia internacional. Nas organizações internacionais, atuam representantes oficiais de governos nacionais; na Carta das Nações Unidas e nas de outras organizações regionais e internacionais, o princípio da autodeterminação nacional e da independência está inscrito de forma destacada. As organizações supranacionais também podem ser usadas para a operação de políticas nacionais. Sobretudo em tempos de crise e sob ameaça interna e/ou externa (Guerra do Golfo, dissolução da União Soviética e da Iugoslávia), requer-se atuação governamental.

O princípio do Estado nacional se superpõe, igualmente, aos movimentos religiosos modernos. Os grandes movimentos federativos, como o pan-islamismo e o pan-arabismo, como, anteriormente, o pangermanismo ou o pan-eslavismo, fracassaram porque os interesses dos Estados nacionais foram mais fortes. Esses movimentos étnico-religiosos podem colocar o Estado nacional em questão quando forem instrumentalizados por políticos em busca de poder. O poder pacificador interno do Estado, nesses casos, é importante.

A percepção mesma, a compreensão ou incompreensão de integrantes de outras nacionalidades dá-se, no mais das vezes, mediante representações nacionais consagradas (imagens, estereótipos), que constituem, por assim dizer, fator de coesão e facilitam a orientação, mas também podem induzir a percepções equivocadas. Outros grupos de referência recorrem a esses procedimentos somente de forma restrita.

Também os movimentos regionalistas dentro dos países europeus acabaram por reforçar os componentes nacionalistas. O "retorno" aos modelos culturais originários retomou e acentuou elementos típicos do nacionalismo estatal como língua, religião, história etc. como instituidores de identidade. As exigências de 
mais autonomia, de mais liberdade cultural, de mais prosperidade econômica são dirigidas ao Estado central e constituem bens que seguem administrados por este. De outro lado, os movimentos regionalistas trazem o risco de implodir a coesão do Estado nacional se a discriminação suscitar tendências separatistas.

Como destinatário principal do bem-estar, como poder instituidor de paz, como fator de integração e de identificação, no plano interior e exterior, e como quadro de referência de atuação, também nas organizações internacionais, o Estado desempenha um papel decisivo.

\subsection{A transformação da organização estatal}

Nas considerações feitas até agora, o Estado foi analisado no plano dos processos de política externa e de suas conseqüências no plano interno. Neste plano, contudo, deram-se também mudanças importantes para a conformação do Estado democrático moderno. O estado já não é mais o Estado do século 19. Na época contemporânea, é possível identificar cinco modificações ou evoluções globais do Estado, inclusive em seu interior, que co-determinam a capacidade de atuação do Estado nos planos interno e externo: o aumento do número de atores estatais de 50 membros das Nações Unidas em 1945 para 186 em 1997, a democratização e a parlamentarização em diversas partes do mundo, a tendência de crescimento do setor público, a constitucionalização universal e a formação de partidos organizados (mais pormenores em Pfetsch, 1994).

Quais são os efeitos desses processos de mudança sobre a questão que interessa aqui, relativa à legitimação e à capacidade de ação do Estado? A resposta geral é: o sistema dos Estados requer padrões adequados de negociação e decisão, pelos quais se o torna mais legítimo e eficaz.

\subsection{Os instrumentos estatais de operação}

Os regimes democráticos modernos responderam aos quatro desafios esboçados com três instrumentais: na política interna, com meios corporativos e com nacionalismo; na política externa, com a international governance.

Corporativismo: a tese do déficit de capacidade operacional do Estado, como se sabe, já foi formulada nos anos setenta com a tese da ingovernabilidade (Matz, Kielmansegg, Hennis) e significa a perda da autoridade estatal no desempenho de suas tarefas, eventualmente, até contra o poderio dos grupos e corporações sociais. Com a política corporativa, o Estado busca vincular os grupos sociais à formação da vontade e à tomada de decisão; isso leva ao desempenho conjunto dos atores estatais e sociais. Na Alemanha, as duas recessões do pósguerra conduziram a esse modelo de política (ação coordenada). Peter Katzenstein examinou esse mecanismo de reação no caso de Estados menores: estabilidade 
política e flexibilidade econômica dependiam uma da outra. "Sua vulnerabilidade às forças internacionais situadas fora de seu controle levou-os a adaptar instituições políticas corporativas que são um mecanismo institucional de mobilização do consenso necessário para conviver com os custos de mudanças econômicas rápidas” (Katzenstein, 1985, 200). Para a mobilização de recursos no sistema corporativo, dá-se a intermediação de interesses mediante as associações que representam os interesses de seus integrantes perante o Estado e a política governamental perante seus integrantes (Schmidt, 1995, 520). Como instrumento de mobilização para o consenso nacional os sistemas corporativos demonstram sua aptidão. No entanto, tudo isso pressupõe a existência de um consenso básico acerca de valores fundamentais, normas e regras.

Nacionalismo: à ação centrífuga de forças sociais (associações, grupos minoritários, autonomistas etc.) certos estados contrapõem nacionalismos como elementos de coesão. A nação continua sendo a mais importante comunidade instituidora de identidade. O vínculo de pertencimento constitui-se seja através de características subjetivas ou objetivas, seja representado como comunidade "de pensamento" ou "de experiência", seja como "produto de um processo de construção social”, seja, ainda, como expressão da "carência de aconchego, força e estabilidade”. Os grupos conservadores nos países ocidentais inscreveram o nacionalismo em suas bandeiras. A reativação de temas nacionalistas é, sobretudo, um instrumento da formação dos Estados nos países recentemente tornados independentes da antiga União Soviética. Eles provêm, justamente, de um outro extremo da integração regional: enquanto os Estados da Europa ocidental puderam abrir-se para a integração regional européia após a desqualificação do nacionalismo subseqüente à $2^{\mathrm{a}}$ Guerra Mundial, os países do leste europeu percorrem hoje o caminho inverso, do internacionalismo proletário para o nacionalismo.

Esses movimentos de renacionalização são, no entanto, complexos. Raramente, Estado e nacionalidade são congruentes em um país. Mais comumente, existem nacionalismos particulares que não reúnem, mas afastam. Identidades possuem diversos modelos de referência, que podem estar vinculados à região, à etnia, à religião etc. Essas identidades particulares podem levar à desestabilização da coesão do Estado nacional. Nacionalismo como força integradora somente é possível onde as identidades admitam a constituição de um Estado nacional.

International governance (governabilidade): os Estados têm a ganhar, se e sobretudo, quando cooperam entre si. As entidades não-estatais e os Estados têm algo a ganhar a mais de suas interdependências (balanço positivo) e isso não apenas à custa de outros (balanço zero). A definição de poder por Max Weber, como a capacidade de impor sua vontade a outrem, já não é mais adequada hoje, no tempo das relações multilaterais. International governance significa a capacidade operacional cooperativa de uma comunidade política no âmbito de objetivos comuns às instituições estatais (governos) e não-estatais (sociais) 
participantes. International governance significa a capacidade operacional cooperativa do Estado sob as condições da interdependência social e da integração internacional. A concepção de "governance without government" significa a expansão de um regime internacional para todo e qualquer setor da política (J. N. Rosenau/E.-O. Czempiel, 1992, 8/9). Uma tal cooperação depende, por certo, da renúncia a certos direitos soberanos, mas significa também, no mais das vezes, um ganho. Já no início deste século, o austríaco Alfred H. Fried, prêmio Nobel da paz, escreveu: "Na economia mundial hoje tão interligada estado nenhum é completamente independente. Todos os Estados dependem um dos outros pela pressão de suas relações e estão, em certo sentido, limitados em sua atuação. A organização [trata-se da organização internacional, F.P.] regulará essa limitação de poder da forma mais vantajosa para os Estados, na medida em que oferecer compensação da limitação de poder mediante as obrigações assumidas pelos demais Estados” (Fried, 1907).

Mesmo quando ingressam em organizações internacionais, os Estados não perdem sua competência decisória no plano governamental, mesmo se a reduzem ao longo da formação do consenso. Os governos continuam "donos da decisão" em questões importantes. Dois campos servem aqui de exemplo.

Na comunidade de Estados mais intensamente integrada, a União Européia (UE), os governos dos Estados membros continuam sendo os atores principais. No Conselho da Europa e no Conselho de Ministros, os dois órgãos intergovernamentais mais importantes da UE, os governos têm a última palavra nos campos mais importantes da política: a política exterior e a política de segurança. As resoluções nessas matérias somente podem ser adotadas por unanimidade. Enquanto o primeiro pilar, o mercado interno, tornou-se amplamente comunitário - com o que os Estados nacionais cederam competência decisória - os dois outros pilares, a política externa e a política de segurança, assim como a política interna e a justiça, permanecem sob o controle de cada Estado particular. O Tribunal Constitucional Federal [alemão] destacou essa situação em um acórdão de 1993: "Mesmo depois da entrada em vigor do tratado de União, a República Federal [da Alemanha] continua (...) membro de uma federação de estados, cujo poder comunitário provém dos Estados membros e só tem efeito vinculante no território sob soberania alemã por força da lei de aplicação do Direito [comunitário] (Zustimmungsgesetz)”. Pode-se dizer a mesma coisa, no plano subnacional, dos partidos e das associações, que atuam, mesmo na federação européia, sobretudo no contexto nacional.

Também no caso do segundo exemplo, o Conselho de Segurança da ONU, dificilmente são adotadas resoluções contra a vontade de seus integrantes (ver acima). Os governos das grandes potências reservaram para si a última palavra e podem bloquear, mediante veto, qualquer resolução que contradiga seus interesses. Nos conflitos armados, o papel decisivo das grandes potências ficou evidente. Diversos conflitos violentos, como as guerras da Bósnia, demonstraram que, ao 
fim e ao cabo, uma grande potência pode intermediar a paz. Sempre que as organizações internacionais agiram contra um agressor com meios militares tal aconteceu por iniciativa das grandes potências, como na $2^{\mathrm{a}}$ Guerra do Golfo. Tal como está organizada hoje a comunidade internacional dos Estados, o papel das grandes potências como instituidoras da paz é indispensável, pois somente elas podem engajar meios proporcionais em conflitos armados. As guerras da Bósnia e seu encerramento dão testemunho disso. De início, as organizações regionais, a Comunidade Européia e a Conferência para Segurança e Cooperação na Europa, tentaram controlar o conflito e, em seguida, a ONU. Seus meios não bastaram para forçar as partes em conflito a ceder. A solução alcançada nas negociações de Dayton foi buscada e, afinal, imposta pelos Estados Unidos.

\subsection{O deslocamento das competências do Estado}

Os quatro processos, da europeização, da globalização, da individualização e da renacionalização, são processos que não surgiram subitamente. A queda das ditaduras na Europa do Leste tem a ver apenas superficialmente com esses quatro fatores de crise. Trata-se, antes, de processos de longa duração, apenas indiretamente relativos à recente transição. É certo que a situação dos Estados da Europa Central e do Leste sofreu grandes mudanças; é igualmente certo que as relações internacionais na Europa e as entre as antigas superpotências evoluíram significativamente; é não menos certo que a reconstrução nas novas províncias [alemãs] requer grandes esforços. Os problemas econômicos e sociais de hoje, porém, nas democracias ocidentais, foram atingidos apenas de modo superficial pelas rupturas políticas; decisivos são, muito mais, os processos globais.

Os conjuntos de fenômenos indicados permitem identificar tendências em direção tanto da internacionalização quanto dos Estados nacionais. Surgiram tensões tanto nas sociedades ocidentais como não-ocidentais entre modernização e “indigenização" (Huntington), entre universal e particular, entre homogeneização e heterogeneidade. Nesses conflitos internos, o Estado tem, na minha opinião, um papel importante como mediador, árbitro, coordenador e agente do bem comum.

A capacidade de atuação do Estado está ao mesmo tempo erodida e reforçada. Com prudente otimismo, pode-se admitir que a política corporativa no plano interior e a international governance no plano externo recuperam a perda de operacionalidade decorrente dos processos indicados e até mesmo expandem a capacidade de agir. O espaço de atuação do Estado não foi, afinal, meramente restrito, mas deslocou-se. Modelos de política transformaram-se e passaram a outras arenas. Falo aqui da tese do deslocamento - e não de decadência, mas sim de um deslocamento dos espaços de atuação do Estado - que se pode formular, também, como evolução da forma (Maintz).

Com isso não se resolve, o déficit de democracia que se instaurou com a crescente discrepância entre os que mandam e os que são mandados, nos diversos 
contextos internacionais. A congruência existente, nas democracias representativas, entre os titulares do poder e os atingidos pelas decisões, deve ser também instituída no plano internacional. Somente dessa forma pode ser superado o déficit de legitimação. Quanto mais o mundo dos Estados evoluir para uma sociedade mundial tanto maior será a necessidade de restauração da simetria das relações de soberania. A democratização da sociedade mundial está, assim, na agenda da virada para o próximo milênio.

Julho 1998

\section{Nota}

1 Cf. Kramer, Helmut (ed.): Politische Theorie und Ideengeschichte im Gespräch. Viena: WUVUniversitätsverlag, 1995, p. 9-20; Capra, Frijtof: Wendezeit. Munique, 1988. Diz Capra: “No início das duas últimas décadas de nosso século, encontramo-nos em meio a uma crise profunda, de alcance mundial. Trata-se de uma crise multidimensional, plurifacetada, “cujos elementos atingem todos os aspectos de nossas vidas - nossa saúde como modo de vida, a qualidade de nosso meio-ambiente como nossas relações sociais, nossa economia, tecnologia e política. É uma crise das dimensões intelectuais, morais e espirituais...” (p. 15). As citações em alemão ou inglês, no texto, foram traduzidas para o português (N.T.)

\section{Bibliografia}

AXTMANN, Roland. “Globalisierung, Identität und demokratischer Nationalstaat”. In: Leviathan $1 / 1995$.

BARLOEWEN, Constantin von. “Gibst es ein Weltdorf?” In: Frankfurter Allgemeine Zeitung (FAZ), 8.3.1996.

BELL, Daniel. In: Carl Böhret und Göttrik Wewer (eds.). Regieren im 21. Jahrhundert. Zwischen Globalisierung und Regionalisierung. Opladen 1993, p. 11.

BEYME, Klaus von. "Steuerung und Selbstregulierung”. In: Journal für Sozialforschung, vol. 35, 3/4, 1995.

BOYER, Robert e Drache, Daniel (eds.). States against Markets. Londres, Nova Iorque, 1996.

BULL, Hedley. The Anarchical Society. Londres: Macmillan, 1977.

BUSCH, Andreas. "Globalisation: Theoretical Issues and Measurement”. Paper, Conference on Globalisation, Welfare States and Labour Markets, Heidelberg, Sept. 1996.

CAPRA, Fritjof. Wendezeit. Munique: Knaur, 1998.

DAHRENDORF, Ralf. “Rule, Germany, Rule the Dreams”. In: FAZ, 29.10.1996.

FRIED, Alfred H. Die moderne Friedensbewegung. Aus Natur und Geisteswelt. Leipzig, 1907.

FRIEDMAN, Thomas L. “Don’t Leave Globalisation's Losers Out of Mind”. In: Herald Tribune, 18.7.1996.

GLYN, Andrew. “Social Democracy and Full Employment”. In: New Left Review 211, 1995, p. 33-55.

HABERMAS, Jürgen. Die neue Unübersichtlichkeit. Frankfurt: Suhrkamp, 1987.

HENNIS, Wilhelm (ed.). Regierbarkeit. 2 vols., 1977. 
HERTZ, John H. “The Territorial State Revised: Reflections ond the Future of the Nation-State”. In: James ROSENAU (ed.). International Politics and Foreign Policy. Nova Iorque: Free Press, 1969.

HUNTINGTON, Samuel P. The Third Wave. Democratization in the Late Twentieth Century. Oklahoma, 1991.

KATZENSTEIN, Peter J. Small States in World Markets. Ithaca, 1985.

KOHL, Jürgen. "Die öffentlichen Ausgaben und ihre Finanzierung”. In: O. W. Gabriel (ed.). Die EG-Staaten im Vergleich. Opladen, 1992.

KRAMER, Helmut (ed.). Politische Theorie und Ideengeschichte im Gespräch. Viena, 1995.

MCGREW, Anthony G./Lewis, Paul G. Global Politics. Cambridge: Polity, 1993 (repr.).

MARTIN, Hans-Peter und Schumann, Harald. Die Globalisierungsfalle. Hamburgo, 1996.

MENZEL, Ulrich. "Wenn sich die Finanzwelt von der Warenwelt verselbständigt”. In: Frankfurter Rundschau (FR), 5.10.1996.

MÜLLER, Michael. “Die Ökonomie frisst die Demokratie”. In: FR, 18.9.1996.

OHMAE, Kenichi. “The Borderless World”. Harper-Business, 1990.

PFETSCH, Frank R./Billing, Peter. Datenhandbuch nationaler und internationaler Konflikte. BadenBaden: Nomos, 1994.

PFETSCH, Frank R. Internationale Politik. Stuttgart: Kohlhammer, 1994.

ROSENAU, J.N./Czempiel, E.-O. Governance without Government: Order and Change in World Politics. 1992.

SACHS, Jeffrey and Warner, Andrew. “Economic Reform and the Process of Global Integration”. In: Brookings Papers on Economic Activity 1/1995.

SCHARPF, Fritz. “Die Handlungsfähigkeit des Staates am Ende des zwanzigsten Jahrhunderts”. In: PVS 1991, p. 621-634.

SCHARPF, Fritz. "Mehrebenenpolitik im vollendeten Binnenmarkt”. In: Staatswissenschaft und Staatspraxis 5/4, 1994, p. 475-502.

SCHMIDT, Manfred G. Wörterbuch zur Politik. Stuttgart: Kröner, 1995.

STRANGE, Susan. “The Limits of Politics”. In: Government and Opposition 30, 1995, p. 291-311.

VANHANEN, Tatu. The Emergence of Democracy. A Comparative Study of 119 States, 1850-1979. Helsinki, 1984.

WALLACE, Helen/Wallace, William. Policy-Making in the European Union. Oxford, 1996.

WEILER, J.H.H. “The Transformation of Europe”. Yale Journal, 100/8, 2403-83

WESSELS, W. "Staat und (westeuropäische) Integration: Fusionsthese”. PVS Sonderheft 23/92, p. 36-61.

\section{Resumo}

O texto faz uma reflexão sobre ambas a capacidade de agir e a legitimidade do Estado democrático de direito no mundo contemporâneo. Considera aspectos tais como a globalização, a regionalização e a individualização, levando em conta as funções do Estado, seus instrumentos de operação e suas novas competências.

\section{Abstract}

The text brings a reflection about both the ability to act and the legitimacy of the democratic Rule of Law (Verfassungsstaates) in the contemporary world. 
It considers aspects such as globalization, regionalization, and individualization, looking upon State functions, its instruments for action and its new competence.

Palavras-chave: Estado democrático de direito. Legitimidade. Capacidade de atuação. Globalização.

Key-words: Democratic Rule of Law. Legitimacy. Ability to act. Globalization. 